\title{
Synthesis and evaluation of antioxidant and antibacterial activities of new substituted bis(1,3,4-oxadiazoles), 3,5-bis(substituted) pyrazoles and isoxazoles
}

\author{
Ebraheem Abdu Musad ${ }^{\mathrm{a}}$, Riyaz Mohamed ${ }^{\mathrm{b}}$, Bahjat Ali Saeed ${ }^{\mathrm{c}}$, Bannikuppe S. Vishwanath ${ }^{\mathrm{b}}$, \\ K. M. Lokanatha Rai ${ }^{\mathrm{a}, *}$ \\ a Department of Studies in Chemistry, University of Mysore, Manasagangotri, Mysore 570 006, India \\ ${ }^{\mathrm{b}}$ Department of Studies in Biochemistry, University of Mysore, Manasagangotri, Mysore 570 006, India \\ ${ }^{\mathrm{c}}$ Department of Chemistry, College of Education, University of Basrah, Basrah, Iraq
}

\section{A R T I C L E I N F O}

\section{Article history:}

Received 18 March 2011

Revised 27 April 2011

Accepted 29 April 2011

Available online 6 May 2011

\section{Keywords:}

Methylene-linked bis(1,3,4-oxadiazole)

derivatives

3,5-Bis(substituted) pyrazoles

Isoxazoles

Antioxidant

Antibacterial

\begin{abstract}
A B S T R A C T
Two series of five membered heterocyclic bis(1,3,4-oxadiazole) derivatives $\mathbf{2}(\mathbf{a}-\mathbf{h})$ and 3,5-bis(substituted)pyrazoles, isoxazoles $\mathbf{3}(\mathbf{a}, \mathbf{b}, \mathbf{d}-\mathbf{i}), \mathbf{4}(\mathbf{a}-\mathbf{c})$ were synthesized via oxidative cyclization of some diaroylhydrazones using chloramine- $\mathrm{T}$ and cyclocondensation reaction with hydrazine hydrate and hydroxylamine hydrochloride, respectively. The newly synthesized compounds were screened for antioxidant and anti-microbial activities. Compounds $\mathbf{2}(\mathbf{b}), \mathbf{3}(\mathbf{b})$, and $\mathbf{4}(\mathbf{a})$ showed higher antioxidant activity at $10 \mu \mathrm{g} / \mathrm{ml}$ while compounds $\mathbf{2}(\mathbf{a}), \mathbf{3}(\mathbf{a}), \mathbf{3}(\mathbf{f})$, and $\mathbf{4}(\mathbf{a})$ exhibited better anti-microbial activity at $100 \mu \mathrm{g} / \mathrm{ml}$ compared with standard vitamin $C$ and ciprofloxacin, respectively. Structures of newly synthesized compounds were confirmed by elemental analysis and spectral IR, ${ }^{1} \mathrm{H}$ NMR, and ${ }^{13} \mathrm{C}$ NMR data.
\end{abstract}

(c) 2011 Elsevier Ltd. All rights reserved.
The wide occurrence of the heterocycles in bioactive natural products, pharmaceuticals, and agrochemicals ${ }^{1,2}$ has made them as important synthetic targets. 1,3,4-Oxadiazoles, pyrazoles, and isoxazoles represent a class of heterocyclic compounds of great importance in biological chemistry. For instance, compounds possessing 1,3,4-oxadiazole, pyrazole, and isoxazole moiety show anticancer $^{3-6}$ activity. Substituted 1,3,4-oxadiazoles, pyrazoles and isoxazoles have revealed antibacterial, ${ }^{7-9}$ antioxidant, ${ }^{8-11}$ insecticidal properties, etc. ${ }^{12-14}$ Literature studies reveal that 2,5-disubstituted-1,3,4-oxadiazoles have been synthesized either by microwave irradiation of hydrazide and carboxylic acid mixture ${ }^{15}$ or by thermal/acid catalyzed cyclization of 1,2-diacylhydrazines. ${ }^{16}$ 2,5-Disubstituted-1,3,4-oxadiazoles have also been synthesized by oxidative cyclization of semicarbazone/hydrazone using chloramines-T as an oxidant. ${ }^{17}$ Cyclocondensation reactions are useful tools for constructing pyrazoles and isoxazoles ${ }^{18,19}$ cyclocondensation of hydrazine hydrate and hydroxylamine hydrochloride to $\beta$ diketones is of synthetic interest, since the products 3,5-disubstituted pyrazoles, 3,5-disubstituted isoxazoles, and their derivatives obtained are the versatile intermediates for the synthesis of bifunctional compounds. The literature survey leading to synthesis of

\footnotetext{
* Corresponding author. Tel.: +91 9972165994; fax: +91 8212421263

E-mail address: alhashmi.ibrahim@yahoo.com (K.M. Lokanatha Rai).
}

methylene-linked bis(1,3,4-oxadiazol) and 3,5-bis(substituted) pyrazole, 3,5-bis(substituted)isoxazole indicate the lack of reference available. In our laboratory Rai et al. extensively used chloramines-T for the generation 2,5-disubstituted-1,3,4-oxadiazoles from acylhydrazones. ${ }^{20}$ On the other hand, we have recently reported the synthesis of 3,5-bis(substituted)pyrazoles and 3,5-bis(substituted)isoxazoles via cyclocondensation reaction of hydrazine hydrate, hydroxylamine hydrochloride with some diaroylhydrazones under selevothermal conditions. ${ }^{21}$ With this background, it is considered worthwhile to prepare bis(heterocycle) bearing 1,3,4-oxadiazole moieties furthermore 3,5-bis(substituted) pyrazoles and isoxazoles starting from simple diaroylhydrazones and screen them for antioxidant and antibacterial activities. The present report deals with the synthesis and biological evaluation of hitherto unknown methylene-linked bis (heterocycle) bearing 1,3,4-oxadiazole moieties.

The desired starting material malonodihydrazide was prepared by condensation of diethylmalonate with hydrazine hydrate in a molar ratio of $1: 2$, under refluxing ethanol. The resultant was subjected to other condensation with corresponding aromatic aldehydes by employing a well known method available in the literature $^{22}$ afforded diaroylhydrazones $\mathbf{1}(\mathbf{a}-\mathbf{i})$ (Scheme 1).

The oxidation of diaroylhydrazones $\mathbf{1}(\mathbf{a}-\mathbf{i})$ with chloramines-T in a molar ratio of 1:2 to generate nitrile imines followed by intramolecular cyclization with adjacent carbonyl groups yielded the 
<smiles>CCOC(=O)CC(=O)OCC</smiles>

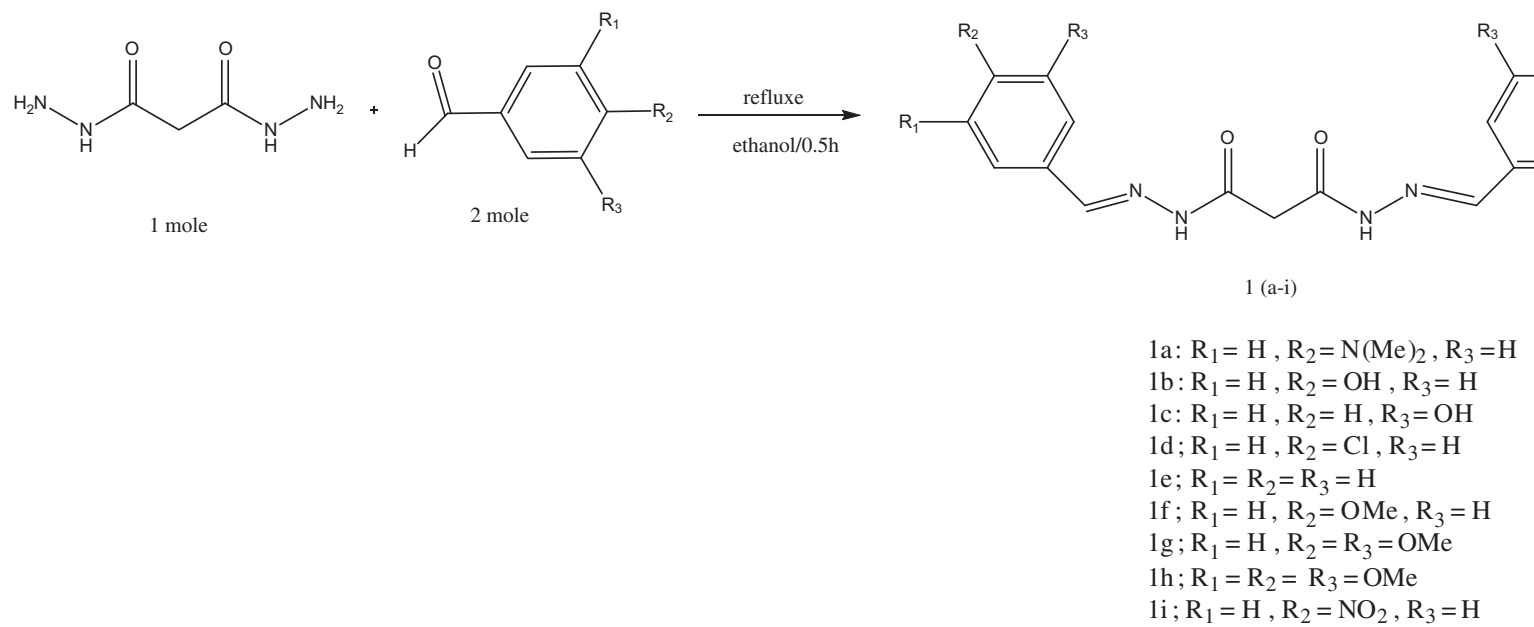

Scheme 1. Synthesis of $\left(N^{\prime 1} E, N^{\prime 3} E\right)-N^{1}{ }^{1} N^{3}$-dibenzylidenemalonohydrazide derivatives.

methylene-linked bis(1,3,4-oxadiazole) derivatives $\mathbf{2}(\mathbf{a}-\mathbf{h})$ which were identified by NMR spectroscope (Scheme 2 ).

The diaroylhydrazones were $\mathbf{1}(\mathbf{a}-\mathbf{b}, \mathbf{d}-\mathbf{i})$ further treated with hydrazine hydrate, meanwhile the diaroylhydrazones $\mathbf{1}(\mathbf{a}, \mathbf{d}, \mathbf{h})$ were treated with hydroxylamine hydrochloride to get the desired products $\mathbf{3}(\mathbf{a}, \mathbf{b}, \mathbf{d}-\mathbf{i})$ and $\mathbf{4}(\mathbf{a}-\mathbf{c})$ (Scheme 3 ). The probable mechanism of formation of isoxazoles $\mathbf{4}(\mathbf{a}-\mathbf{c})$ involves the attack of nitrogen atom of hydroxylamine hydrochloride on the carbonyl carbon that follows the oxime pathway to yield the intermediate which undergoes intramolecular cyclization $\mathbf{4}(\mathbf{a}-\mathbf{c})$.

${ }^{1} \mathrm{H}$ NMR spectra of compounds $\mathbf{2}(\mathbf{a}-\mathbf{h})$ showed singlets in the region of $\delta 2.86-3.35 \mathrm{ppm}$ that correspond to $-\mathrm{CH}_{2}$ - group attached to the oxadiazole rings. Aromatic protons and other substituents are at the expected region. ${ }^{23}$

According to the ${ }^{1} \mathrm{H}$ NMR spectra of compounds $\mathbf{3}(\mathbf{a}, \mathbf{b}, \mathbf{d}-\mathbf{i})$ and $\mathbf{4}(\mathbf{a}-\mathbf{c})$ also showed singlets in the region of $\delta 7.27-8.60 \mathrm{ppm}$ that correspond to methine protons of pyrazole and isoxazole rings, other singlets appear in the $\delta 7.56-8.79 \mathrm{ppm}$ region that correspond to the methane proton adjacent to phenyl rings. Furthermore the ${ }^{1} \mathrm{H}$ NMR of pyrazoles $\mathbf{3}(\mathbf{a}, \mathbf{b}, \mathbf{d}-\mathbf{i})$ showed broad signals in the region of $\delta 9.00-12.28 \mathrm{ppm}$ that correspond to amino proton of hydrazide and pyrazole rings. Aromatic protons and other substituents are at the expected region. The IR spectrum of oxadiaz- oles $\mathbf{2}(\mathbf{a}-\mathbf{h})$ showed the absence of $\mathrm{NH}$ frequency in the region $3100-3200 \mathrm{~cm}^{-1}$ and showed a new peak at $1581-1678 \mathrm{~cm}^{-1}$ due to $\mathrm{C}=\mathrm{N}$ frequency that confirms the formation of the products. The ${ }^{13} \mathrm{C}$ NMR and elemental data analysis further confirm the structures of the desired products.

The 2,2-diphenyl-1-picryl-hydrazyl ( $\left.\mathrm{DPPH}^{-}\right)$radical scavenging activity (RSA) evaluation is a standard assay in antioxidant activity studies and offers a rapid technique for screening the RSA of specific compounds or extracts. ${ }^{24-27}$ The interaction of synthesized bis(1,3,4-oxadiazole) series $\mathbf{2}(\mathbf{a}-\mathbf{h})$ with stable DPPH free radical indicates their free radical scavenging ability. Majority of the tested compounds in these series showed low to moderate interaction with the DPPH radical at $10 \mu \mathrm{g} / \mathrm{mL}$ concentration. Maximum DPPH RSA was observed in compound $2(\mathbf{e})(p<0.05)$, which does not have a substituent on the phenyl ring (Table 1$)$. The presence of either electron-donating or electron-withdrawing groups on the phenyl ring at positions 3,4,5 might not favor the activity. Compounds 2 (a-d) which contain $-\mathrm{N}\left(\mathrm{CH}_{3}\right)_{2}$ or $-\mathrm{OH}$ or $\mathrm{Cl}$ groups on the phenyl ring at position 4 showed low to moderate radical scavenging activity but lower than compound $2(\mathbf{e})$, whereas the compounds $\mathbf{2}(\mathbf{f}-\mathbf{h})$ that contain methoxy groups on the phenyl ring at positions 3,4,5, did not show any activity. On the other hand, the 3,5-bis(substituted) pyrazoles and isoxazoles series $\mathbf{3}(\mathbf{a}, \mathbf{b}, \mathbf{d}-$

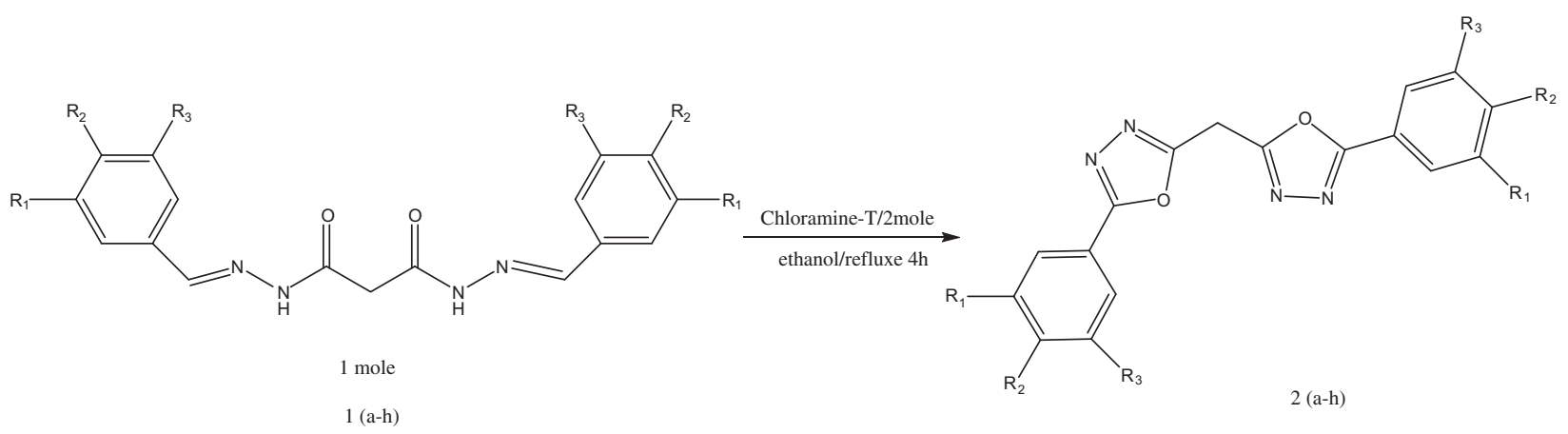

Scheme 2. Synthesis of bis(1,3,4-oxadiazole) derivatives. 


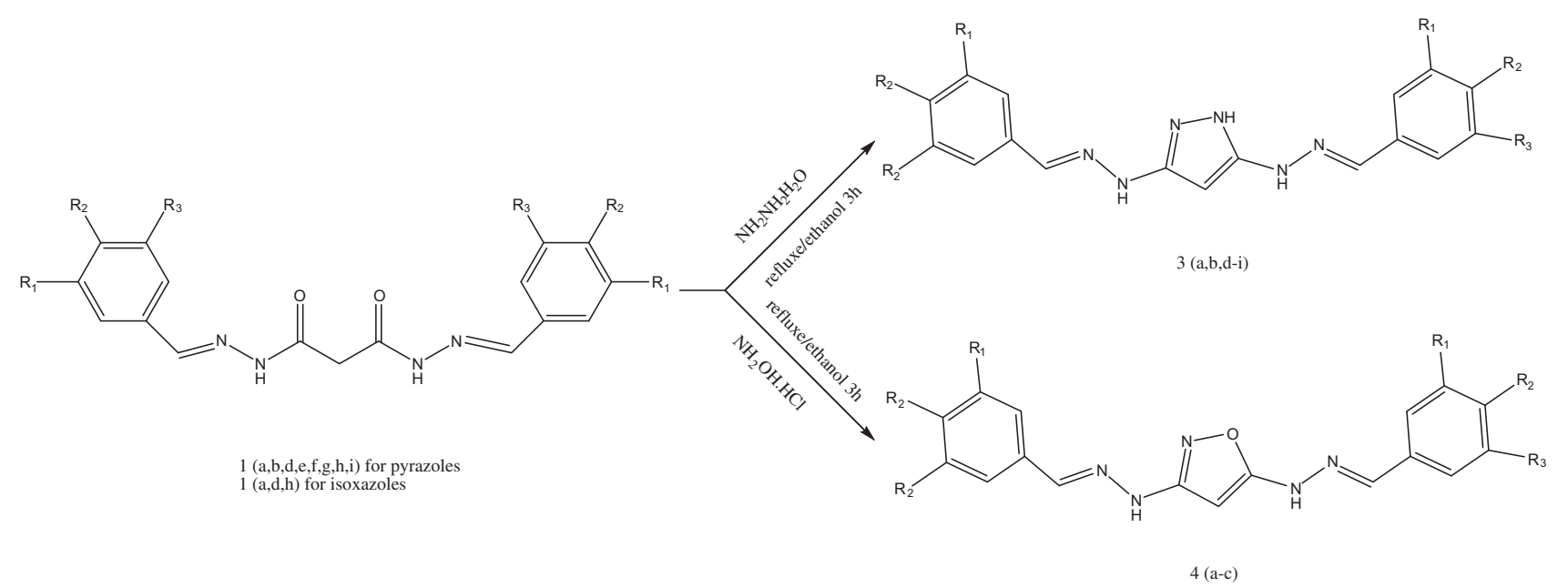

Scheme 3. Synthesis of 3,5-bis(substituted)pyrazoles and isoxazoles.

Table 1

Antioxidant activity of synthesized novel series of bis(1,3,4-oxadiazole) derivatives (2a-h) and 3,5-bis(substituted) pyrazoles (3a,b,d-i) and isoxazoles derivatives (4a-c)

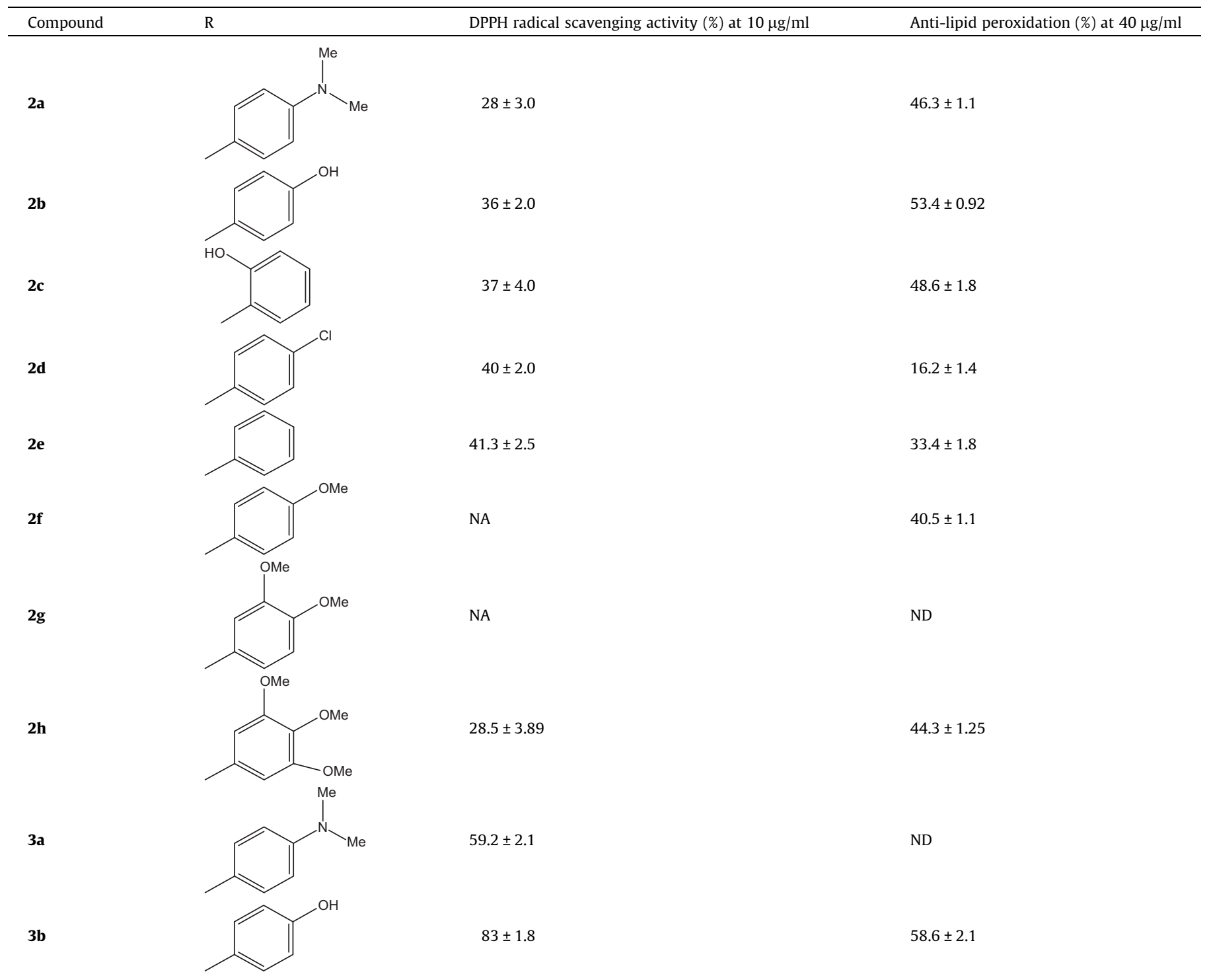


Table 1 (continued)

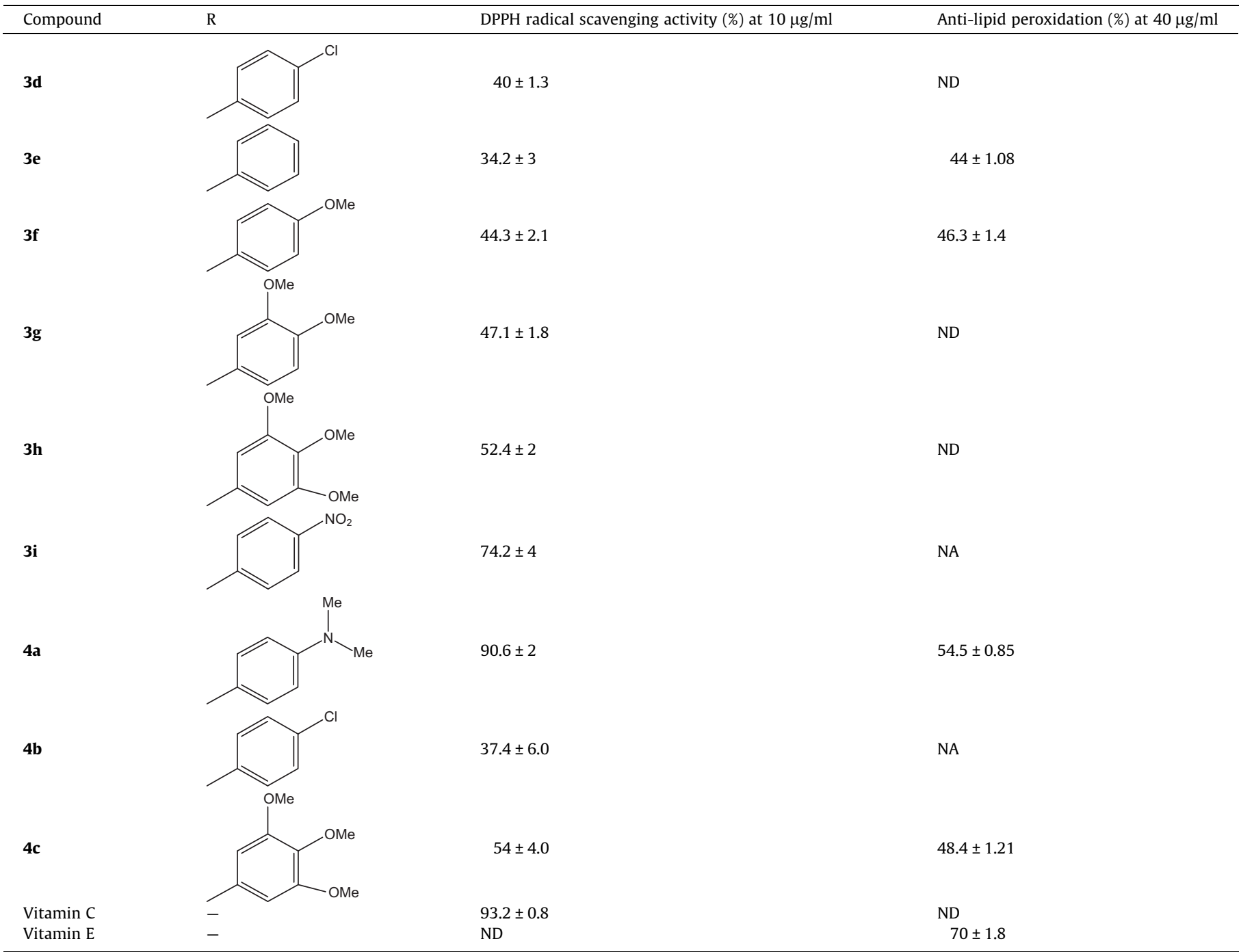

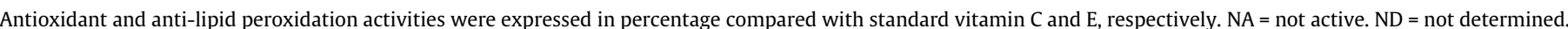
The data represent mean value (SEM) of three duplicates.

i), $\mathbf{4}(\mathbf{a}-\mathbf{c})$ showed scavenging of DPPH radical at varying degrees when compared with the standard antioxidant vitamin $C$. The results are represented in Table 1 . The maximum antioxidant activity was observed in compounds in the following order $\mathbf{4}(\mathbf{a})>\mathbf{3}(\mathbf{b})>\mathbf{3}(\mathbf{i})$, which is comparable to that of standard vitamin $C$ at a similar concentration. The other eight compounds exhibited good to moderate RSA in the order $\mathbf{3}(\mathrm{a})>\mathbf{4}(\mathbf{c})>\mathbf{3}(\mathrm{h})>$ $\mathbf{3}(\mathbf{g})>\mathbf{3}(\mathbf{f})>\mathbf{3}(\mathbf{d})>\mathbf{4}(\mathbf{b})>\mathbf{3}(\mathbf{e})$ (Table 1$)$. The presence of either electron-donating or electron-withdrawing groups on the phenyl ring mostly favor the activity particularly with a strong electrondonating group such as $-\mathrm{N}\left(\mathrm{CH}_{3}\right)_{2}$ or a strong electron-withdrawing group such as $\mathrm{NO}_{2}$. Antioxidant activity of these compounds is related with their electron or hydrogen radical donating ability to DPPH radical, so that they become stable diamagnetic molecules. This might be the reason for the higher antioxidant activity of the second series of compounds $\mathbf{3}(\mathbf{a}, \mathbf{b}, \mathbf{d}-\mathbf{i})$ and $\mathbf{4}(\mathbf{a}-\mathbf{c})$.

Evaluation of anti-lipid peroxidation property of newly synthesized compounds was performed by the formation of thiobarbituric acid reactive species (TBARS) using egg yolk homogenate as lipid-rich media. The result showed that all newly synthesized compounds inhibited the ferric chloride-induced lipid peroxida- tion at $40 \mu \mathrm{g} / \mathrm{mL}$ concentration with a varying degree when compared with standard biological antioxidant vitamin E (Table 1). Compound $\mathbf{2}(\mathbf{b}),(p<0.05)$ which has $-\mathrm{OH}$ group on the phenyl ring at position 4 showed maximum inhibition. However, inhibition activity was found to be lower than that of the reference compound vitamin E. Compound $\mathbf{2}(\mathbf{d})$, which has chlorine as the electron-withdrawing substituent on phenyl ring at position 4, exhibited the lowest inhibition. In general, it appears that the presence of electron-donating groups on the phenyl ring favors the activity. This might be the reason for the enhancement of activity of the other compounds, which showed moderate activities in the order $\mathbf{2}(\mathbf{c})>\mathbf{2}(\mathbf{a})>\mathbf{2}(\mathbf{h})>\mathbf{2}(\mathbf{f})$. However, compound $\mathbf{2}(\mathbf{e})$ was found to show lower activity when compared with compound $\mathbf{2}(\mathbf{c}), \mathbf{2}(\mathbf{a}), \mathbf{2}(\mathbf{h})$, and $\mathbf{2}(\mathbf{f})$, since it does not have a substituent on the phenyl ring. Further, synthesized pyrazole $\mathbf{3}(\mathbf{a}, \mathbf{b}, \mathbf{d}-\mathbf{i})$ and isoxazoles $\mathbf{4}(\mathbf{a}-\mathbf{c})$ series showed that majority of the compounds had moderate inhibitive action, which follows the order $\mathbf{3}(\mathbf{b})>\mathbf{4}(\mathbf{a})>\mathbf{4}(\mathbf{c})>\mathbf{3}(\mathrm{g})>\mathbf{3}(\mathbf{e})$ (Table 1$)$. In these series, the presence of the electron-donating group on the phenyl ring at position 4 such as $-\mathrm{N}\left(\mathrm{CH}_{3}\right)_{2},-\mathrm{OH}$ and $-\mathrm{OMe}$ at positions 3,4,5 enhanced the activity when compared to the activity of compound $3(\mathbf{e})$. The 
Table 2

Antibacterial activity of synthesized novel series of pyrazoles and isoxazoles derivatives (2a-h, 3a,b,d-i and $\mathbf{4 a - c})$

\begin{tabular}{lrrrr}
\hline Compound & S. aureus & B. subtilis & E. coli & P. aeruginosa \\
\hline $\mathbf{2 a}$ & $13 \pm 0.56$ & $12 \pm 1.24$ & $10 \pm 0.86$ & $9 \pm 1.65$ \\
$\mathbf{2 b}$ & $7 \pm 0.25$ & $2 \pm 1.5$ & $1 \pm 0.97$ & $1 \pm 1.27$ \\
$\mathbf{2 c}$ & $9 \pm 1.32$ & $13 \pm 1.16$ & $8 \pm 1.35$ & $5 \pm 0.85$ \\
$\mathbf{2 d}$ & $4 \pm 0.52$ & $6 \pm 0.98$ & $\mathrm{NA}$ & $\mathrm{NA}$ \\
$\mathbf{2 e}$ & $7 \pm 1.32$ & $10 \pm 0.73$ & $5 \pm 0.93$ & $13 \pm 1.24$ \\
$\mathbf{2 f}$ & $9 \pm 1.65$ & $8 \pm 1.16$ & $6 \pm 0.89$ & $7 \pm 1.07$ \\
$\mathbf{2 g}$ & $10 \pm 0.89$ & $11 \pm 1.07$ & $10 \pm 1.31$ & $9 \pm 1.29$ \\
$\mathbf{2 h}$ & $7 \pm 1.32$ & $3 \pm 0.58$ & $\mathrm{NA}$ & $\mathrm{NA}$ \\
$\mathbf{3 a}$ & $20 \pm 0.72$ & $10 \pm 1.24$ & $9 \pm 1.52$ & $8 \pm 1.06$ \\
$\mathbf{3 b}$ & $\mathrm{NA}$ & $7 \pm 1.07$ & $13 \pm 1.32$ & $18 \pm 0.53$ \\
$\mathbf{3 d}$ & $4 \pm 1.16$ & $6 \pm 0.89$ & $4 \pm 1.03$ & $5 \pm 1.37$ \\
$\mathbf{3 e}$ & $5 \pm 1.07$ & $9 \pm 1.29$ & $4 \pm 1.03$ & $9 \pm 1.65$ \\
$\mathbf{3 f}$ & $28 \pm 1.73$ & $20 \pm 0.83$ & $18 \pm 0.58$ & $19 \pm 0.73$ \\
$\mathbf{3 g}$ & $10 \pm 1.37$ & $8 \pm 1.16$ & $13 \pm 1.23$ & $6 \pm 0.87$ \\
$\mathbf{3 h}$ & $17 \pm 1.07$ & $12 \pm 1.05$ & $\mathrm{NA}$ & $9 \pm 1.47$ \\
$\mathbf{3 i}$ & $9 \pm 1.65$ & $7 \pm 1.12$ & $11 \pm 1.09$ & $8 \pm 0.67$ \\
$\mathbf{4 a}$ & $20 \pm 0.72$ & $15 \pm 1.81$ & $10 \pm 1.24$ & $12 \pm 0.89$ \\
$\mathbf{4 b}$ & $14 \pm 0.96$ & $8 \pm 0.73$ & $8 \pm 1.14$ & $6 \pm 0.76$ \\
$\mathbf{4 c}$ & $13 \pm 0.54$ & $10 \pm 1.09$ & $11 \pm 0.67$ & $9 \pm 0.87$ \\
Ciprofloxacin & $29 \pm 0.85$ & $18 \pm 1.25$ & $26 \pm 1.31$ & $18 \pm 0.89$ \\
\hline
\end{tabular}

Zone of inhibition in mm. Gram-positive bacterial strains: S. aureus-Staphylococcus aureus; B. subtillis-Bacillus subtillis. Gram-negative bacterial strains: E. coli-Escherichia coli; $P$. aeruginosa-Pseudomonas aeruginosa. The concentration of test compounds was $100 \mu \mathrm{g} / \mathrm{mL}$. Solvent which used DMSO. NA = not active. ND = not determined. The data represent mean value (SEM).

presence of a strong electron-withdrawing group like nitro group on the phenyl ring at position 4 did not favor the activity. This might be the reason for the inactivity of compound $\mathbf{3}(\mathbf{i})$.

The synthesized compounds were evaluated for in vitro antimicrobial activity against various bacterial strains using the agar disc diffusion method. The results are presented in Table 2 . The result showed that compounds 2(a), 3(a), 3(f), and 4(a) exhibited maximum antibacterial activity against all the tested microorganisms at a concentration of $100 \mu \mathrm{g} / \mathrm{mL}$ similar to that of the standard antibiotic ciprofloxacin. The activity is considerably affected by substituents present at the para position of phenyl ring. It has been observed that the presence of a strong electron-donating group specially $-\mathrm{N}\left(\mathrm{CH}_{3}\right)_{2}$ group enhances the electron conjugation throughout the structure. The conjugation of electrons through the compound $\mathbf{3}(\mathbf{f})$ is faster than the compounds $\mathbf{2}(\mathbf{a}), \mathbf{3}(\mathbf{a})$, and $\mathbf{4}(\mathbf{a})$. This might be the reason of the highly active of compound $\mathbf{3}(\mathbf{f})$ than other substituents at same position. Also the results in Table 2 revealed that the absence of substituents on the phenyl ring and the presence of strong electron-withdrawing group such as $\mathrm{NO}_{2}$ and $\mathrm{Cl}$ groups also did not favor the activity.

Bis(1,3,4-oxadiazole)derivatives $\mathbf{2}(\mathbf{a}-\mathbf{h})$ and 3,5-bis(substituted)pyrazoles or isoxazoles $\mathbf{3}(\mathbf{a}, \mathbf{b}, \mathbf{d}-\mathbf{i})$ and $\mathbf{4}(\mathbf{a}-\mathbf{c})$ were synthesized and their in vitro antibacterial and antioxidant activities have been evaluated. Compounds $2(\mathbf{b}), \mathbf{3}(\mathbf{b})$, and $\mathbf{4}(\mathbf{a})$ having hydroxyl and $N, N$ dimethyl moiety at para position demonstrated potent antioxidant and anti-lipid peroxidation while compounds 2(a), 3(a), 3(f), and 4(a) showed maximum antibacterial activity in comparison with their corresponding standard drug. Further detailed studies are required to understand the mechanism of action of these compounds.

\section{Acknowledgments}

Author expresses his sincere gratitude to the Council of Scientific and Industrial research, India for financial assistance and University of Mysore, Mysore, for providing the laboratory facilities to carry out this work.

\section{Supplementary data}

Supplementary data associated with this article can be found, in the online version, at doi:10.1016/j.bmcl.2011.04.142.

\section{References and notes}

1. He, D. H.; Zhu, Y. C.; Yang, Z. R.; Xihu, A. J. Chin. Chem. Soc. 2009, 56, 268.

2. Tully, W. R.; Gardner, C. R.; Gillespie, R. J.; Westwood, R. J. Med. Chem. 1991, 34 2060.

3. Bhatt, J. J.; Shah, B. R.; Shah, H. P.; Trivedi, P. B.; Undavia, N. K.; Desai, N. C. J. Indian Chem. 1994, 33B, 189.

4. Kumar, A.; D’Souza, S. S.; Gaonkar, S. L.; Rai, K. M.; Salimath, B. P. Invest. New Drugs 2008, 26, 425.

5. Manfrendini, S.; Bazzanini, R.; Baraldi, P.; Bonora, M.; Marangoni, M.; Simoni, D.; Pani, A.; Scintu, F.; Pinna, E.; Pisana, L.; Lo-Colla, P. Anticancer Drug Res. 1996, 11, 193.

6. Lee, Y. S.; Park, S. M.; Kim, H. M.; Park, S. K.; Lee, K. Bioorg. Med. Chem. Lett. 2009, 19, 4688.

7. Anjani, S.; Yogesh, P. R. Rasayan J. Chem. 2009, 2, 23.

8. Kang, A. Y.; Shin, J. K.; Yoo, H. K.; Seo, J. K. Bioorg. Med. Chem. Lett. 2000, 10, 95

9. Bondock, S.; Fadaly, W.; Metwally, M. A. Eur. J. Med. Chem. 2009, 44, 4813.

10. Manojkumar, P.; Ravi, T. K.; Chettiar, G. S. Acta Pharm. 2009, 55, 159.

11. Rajasekaran, S.; Rao, G. K.; Pai, S.; Vedavathy, J. J. Chem. Pharm. Res. 2010, 2, 101

12. Zheng, X.; Li, Z.; Wang, Y.; Chen, W.; Huang, O.; Liu, C.; Song, C. J. Fluorine Chem. 2003, 123, 163.

13. Li, Y.; Zhang, Q. H.; Liu, J.; Yang, X. P.; Liu, Z. J. J. Agric. Food Chem. 2006, 54 3636.

14. Siddall, T. L.; Quse, D. G.; Benko, Z. L.; Garvin, G. M.; Jackson, J. L.; McQuiston, J. M.; Ricks, M. J.; Thibault, T. D.; Tumer, J. A.; VanHeertum, J. C.; Weimer, M. R. Pest Manag. Sci. 2002, 58, 1175.

15. Khan, K. M.; Zia Ullah; Rani, M.; Perveen, S.; Haider, S. M.; Choudary, M. I.; Attaur-Rahman; Voelter, W. Lett. Org. Chem. 2004, 1, 50.

16. Liras, S.; Allen, M. P.; Segelstein, B. E. Synth. Commun. 2000, 30, 437.

17. Gaonkar, S. L.; Rai, K. M. L.; Prabhuswamy, B. Eur. J. Med. Chem. 2004, 41, 841

18. Nishiyama, Y. N.; Nishimura, N.; Kuroyanagi, N.; Macba, I. Carbohydr. Res. 1995, 290, 507.

19. Moreira, D. N.; Longhi, K. L.; Fizzo, C. P.; Bonacorso, H. G.; Zanatta, N.; Martins, M. A. P. Catal. Commun. 2010, 11, 476.

20. Rai, K. M. L.; Linganna, N.; Hassner, A.; Anjanamurthy, C. J. Sci. Soc. Thailand 1996, 22, 71.

21. Musad, E. A.; Rai, K. M. L.; Pyrappa, K. Int. J. Biomed. Sci. 2010, 6, 100.

22. Rajavel, R.; Senthil, C. M. S.; Antha, C. E.-J. Chem. 2008, 5, 620.

23. Vijay Kumar, H.; Naik, N. Eur. J. Med. Chem. 2010, 45, 2 .

24. Blois, M. S. Nature 1957, 181, 1199.

25. Ruberto, G.; Baratta, M. T.; Deans, S. G.; Dorman, H. J. Planta Med. 2000, 66, 687.

26. Andrews, J. M.BSAC Working Party on Susceptibility Testing J. Antimicrob. Chemother. 2008, 62, 256.

27. Experimental details and characterization data for new compounds are provided in the Supplementary data. 